\section{Estimating Transpiration for Three Woody Ornamental Tree Species using Stem-flow Gauges and Lysimetry}

\author{
D.A. Devitt ${ }^{1}$ and M. Berkowitz \\ Department of Range Wildlife and Forestry, College of Agriculture, University \\ of Nevada Reno, Reno, NV 89557
}

\section{P.J. Schulte}

Department of Biological Sciences, University of Nevada Las Vegas, Las Vegas, NV 89154

\section{R.L. Morris \\ Cooperative Extension, University of Nevada Reno, Las Vegas, NV 89104}

Additional index words. Argentine mesquite, Prosopis alba, desert willow, Chilopsis

linearis, live oak, Quercus virginiana, arid environment, methodology, water use

Abstract. We compared transpiration estimates of three common desert landscape tree species using stem-flow gauges and lysimetry. Argentine mesquite (Prosopis alba Grisebach), desert willow [Chilopsis linearis (cav.) Sweet var. linearis], and southern live oak (Quercus virginiana Mill., seedling selection) were subjected to three irrigation regimes. Leaching fractions of $+\mathbf{0 . 2 5}, \mathbf{0 . 0 0}$, and $\mathbf{- 0 . 2 5}$ were imposed for 2 years. During the summer of the second year, we conducted a comparative transpiration study. Trees growing in 190-liter plastic containers had a highly linear correlation $(r=0.98, P=0.001)$ between transpiration estimated by stem-flow gauges and lysimetry. An average $18 \%$ error was measured between paired data (total runs of 14 to 72.5 hours) of stem-flow gauge and lysimetry transpiration estimates. However, a lower error was correlated significantly with longer run times $(r=\mathbf{- 0 . 3 7}, P=\mathbf{0 . 0 5})$. Based on field measurements taken in this experiment, run times would have to be $>68$ hours to maintain an associated error below $10 \%$. Higher cumulative transpiration also was associated with longer run times $(r=0.80, P=0.001)$. These results suggest that the stem-flow gauge can be used to estimate transpiration accurately to schedule irrigation for woody ornamental trees in an arid environment, provided that irrigation predictions are not based on short-term stem-flow gauge estimates ( $<68$ hours).

Good stewardship of water resources in an arid environment must include accurately scheduled urban landscape irrigation. A major challenge confronting urban irrigation managers is to conserve water while meeting the water requirements of turfgrass, shrubs, and trees growing in landscaped areas. Much information currently is available on turfgrass water use (Biran et al., 1981; Kim and Beard, 1988; Shearman, 1978; Younger et al., 1981). In contrast, little information is available on woody ornamental water use (Heilman and Ham, 1990; Knox, 1989; Steinberg et al., 1990). Research on tree water use using lysimetry (water balance) is the preferred technique for assessing long-term plant water use. However, lysimetry is not an appropriate field

Received for publication 2 June 1992. Accepted for publication 12 Nov. 1992. We thank the Las Vegas Valley Water District for financially supporting this research. We also thank Jeff Andersen and Linda Vanden Heuvel for their assistance in the field and laboratory. The cost of publishing this paper was defrayed in part by the payment of page charges. Under postal regulations, this paper therefore must be hereby marked advertisement solely to indicate this fact.

'Current address: Dept. of Biology, Univ. of Nevada Las Vegas, Las Vegas, NV 89154. the comparative water-use study.

${ }^{2}$ Distance from soil's surface $=7.6 \mathrm{~cm}$.

${ }^{y}$ Measured with a LI-COR LAI-2000 plant canopy analyzer. which tree water use and physiological response were monitored under varying irrigation treatments. Tree height, trunk diameter, and leaf area index (LAI) are listed in Table 1. This research was conducted during the summer of the second year of the larger experiment during which trees were irrigated. Water was applied at rates to maintain leaching fractions (LFs) (drainage volume/irrigation volume) of $+0.25,0.00$, or -0.25 , based on the equation $\mathrm{I}=\mathrm{ET} /(1-\mathrm{LF})$, where $\mathrm{I}$ is the irrigation volume to apply and ET is the measured evapotranspiration. Thus, a soil water deficit was achieved by placing a theoretical negative LF into the equation, thus forcing each week's irrigation to be less than the previous week's ET. ET for the large field study and for the selected trees used in the comparative water-use study was estimated using the hydrologic balance approach of ET $=($ irrigation + precipitation $)-$ drainage change in storage. Change in storage for the comparative water-use study was measured with top-loading balances (Sauter, Germany). Drainage was collected daily by placing a 17$\mathrm{kPa}$ vacuum for $1 \mathrm{~h}$ on two large ceramic extraction cups buried in $10 \mathrm{~cm}$ of diatomaceous earth at the bottom of each container. The three representative trees from each species (one from each irrigation treatment) were moved by a large portable hoist to three toploading balances. The top-loading balances had a reported accuracy of $0.1 \%$ over 0 to 1361 $\mathrm{kg}$ (maximum capacity). Calibration tests were conducted to estimate the error associated with incremental 4000-g weight changes. The error associated with these measurements ranged from $1.06 \%$ to $2.38 \%$

Once the trees had been lifted from their sunken lysimeter positions in the field and placed on the scales, all plastic containers were insulated with R-19 insulation wraps and the soil's surface was fitted with $7.5-\mathrm{cm}$ foam padding, which was then covered with 3-mmthick clear-plastic sheeting. The top-loading balances were wired directly to electronic meters, which were read every $2 \mathrm{~h}$ from 0530 to $1930 \mathrm{HR}$ on days during which daily transpiration patterns were assessed. Otherwise, meters were read every morning at $\approx 0800 \mathrm{HR}$. Twelve weekly runs were conducted (four for each species) between May and August. Run times varied between 14 to $72.5 \mathrm{~h}$. Because of difficulties with one of the top-loading balances and with insulation wraps, only seven of the 12 runs were complete.

Stem-flow gauges (Dynamax, Houston)

Table 1. Size characteristics of three trees for each species growing under three leaching fractions used in

\begin{tabular}{lccccccccccc}
\hline & \multicolumn{10}{c}{ Species } \\
\cline { 2 - 11 } & \multicolumn{1}{c}{ Oak } & \multicolumn{1}{c}{ Leaching fraction } \\
\cline { 2 - 11 } \cline { 3 - 10 } Characteristic & -0.25 & 0.00 & +0.25 & -0.25 & 0.00 & +0.25 & & -0.25 & 0.00 & +0.25 \\
\hline Height $(\mathrm{m})$ & 1.45 & 1.81 & 2.27 & 2.35 & 2.43 & 1.79 & 2.77 & 2.50 & 2.74 \\
Trunk diam $(\mathrm{mm})^{2}$ & 29.1 & 40.2 & 43.3 & 31.0 & 36.7 & 30.9 & 32.1 & 45.4 & 44.2 \\
Leaf area index & 0.34 & 0.84 & 1.01 & 0.42 & 0.39 & 0.39 & 0.35 & 0.63 & 0.29 \\
\hline
\end{tabular}


were attached to the trunk of each tree being weighed. Gauges were wired to a data logger (model CR7; Campbell Scientific, Logan, Utah) for continuous 30-min transpiration estimates during the course of the experiment. The data were then downloaded to a computer for final compilation and statistical analysis. Gauges varied in size according to trunk diameters and were a SGB 1925 or 35 model. All procedures were followed as reported by Steinberg et al. (1989), except, to minimize external energy loading, in addition to insulating the stems above and below the gauges and covering gauges with plastic insulation wraps and aluminum foil, gauges and insulation also were covered with a highly perforated cardboard box for additional radiation protection. On some mesquite trees, damage (discoloration and cankers) to the bark was noted when the gauges were left on for $>2$ days.

LAI was estimated for each tree by using a plant canopy analyzer (model LAI-2000; LICOR, Lincoln, Neb.) at the end of the experiment, based on measuring radiation attenuation as it passed through the canopy.

An automated weather station (Campbell Scientific) was situated in the center of the experimental area. Hourly measurements of solar radiation, maximum and minimum temperature, relative humidity, wind run, and rainfall were downloaded to a computer. The daily Penman combination equation was used (Devitt et al., 1983) to estimate potential evapotranspiration $\left(\mathrm{ET}_{0}\right)$.

All data were analyzed using descriptive statistics, and all correlations were based on linear regression techniques, with correlations considered significant if probabilities were 10.05 .

The tree species varied in their response to irrigation treatment. Mesquite often showed leaf folding during the hottest part of the day under all three irrigation treatments. Leaf chlorosis was observed in desert willow under the highest irrigation treatments, whereas oak dropped leaves and reduced canopy size under deficit irrigation $[\mathrm{LAI}=0.88+0.79(\mathrm{LF}), r=$ $0.66, P=0.05, \mathrm{n}=9]$. Under deficit irrigation, desert willow and mesquite transpired after $1930 \mathrm{HR}$, totaling as much as $9 \%$ to $14 \%$ of the total transpiration for the 24-h period measured using lysimetry. Transpirationafter 1930 HR for willow and mesquite not under deficit irrigation and oak under all irrigation treatments was only $1 \%$ to $5 \%$ of the total 24 -h estimate (statistically different from $9 \%$ to $14 \%)$. This result suggests that when desert willow and mesquite are placed under water deficit (typical of native conditions), they compensate for midday stress by altering their daily transpiration pattern to transpire significant amounts at or around sunset.

$\mathrm{ET}_{0}$ estimated during run times (May to August) varied from 0.69 to $1.30 \mathrm{~cm} \cdot$ day $^{-1}$, with an average of $1.00 \pm 0.18 \mathrm{~cm} \cdot \mathrm{day}^{-1}$. This result reflects typical summer values reported in southern Nevada (Devitt et al., 1992). The relationship between measured transpiration using stem-flow gauges and lysimeters was highly linear $(r=0.98, P=0.001)$, with the regression line almost identical to the 1: 1 line
(Fig. 1). These data represent 30 comparative water-use runs, which varied in total run times between 14 and $72.5 \mathrm{~h}$ (no individual hourly comparisons). Lysimetry transpiration estimates ranged from 994 (14h) to 19,850g (72.5 h). The standard error of estimate associated with stem-flow gauge transpiration for this linear relationship was $1380 \mathrm{~g}$. The average percent error for stem-flow gauge predictions made with this linear relationship, as defined by the standard error of gauge transpiration estimate divided by the average lysimetry value, was $13 \%$. Of the 30 correlation points, 17 were associated with overestimations of transpiration using the stem-flow gauges, while 13 were associated with underestimations (assuming no error attached to the lysimetry estimates). There was a higher association of overestimations of transpiration using the stemflow gauges for desert willow and mesquite ( $70 \%$ of data set for each species) compared to an underestimation of transpiration for oak (70\%). Average percent error for stem-flow estimates based on calculating the error associated with each of the 30 comparative wateruse runs was $18 \%(16.7 \% \pm 9.5 \%$, if one outlier eliminated). This stem-flow gauge error could not be separated by species or irrigation treatment. Due to the over- and underestimation associated with the stem-flow gauges, the error associated with total transpiration estimates for all 30 tree runs was only $1 \%$. However, error associated with the 30 comparisons ranged from $50 \%$ to $0.4 \%$. Stem-flow gauge error was negatively correlated with run time (percent error $=24.94-0.22 \mathrm{X}$, where $\mathrm{X}$ is run time in hours, $r=-0.37$, and $P=0.05$ ). Based on the field measurements taken in this experiment, run times would have to be $>68 \mathrm{~h}$ to maintain an associated error below $10 \%$. Cumulative transpiration estimates typically increased with run times (transpiration in grams $=-1649.7+225.4 \mathrm{X}$, where $\mathrm{X}$ is run time in hours, $r=0.80$, and $P=0.001$ ), such that smaller errors were associated with larger cumulative transpiration estimates. Thus, irrigation scheduling based on transpiration estimates from stem-flow gauges should be a highly reliable technique, if run times are limited to periods $>68 \mathrm{~h}$.

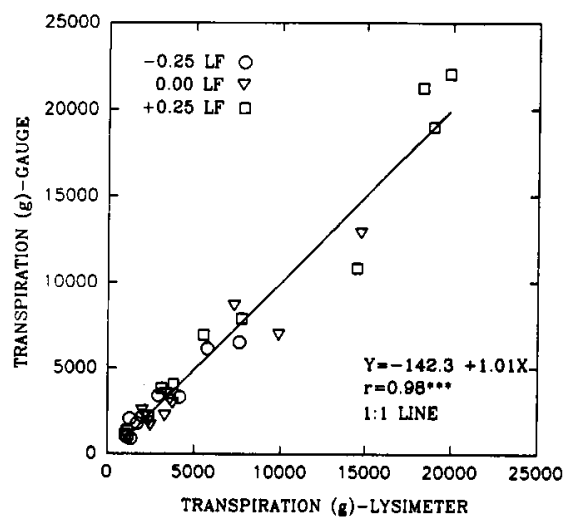

Fig. 1. The relationship between transpiration estimated from stem-flow gauges and lysimetry. The 30 data points represent run times between 14 and $72.5 \mathrm{~h}$. (LF = leaching fraction.)
In addition, no correlation existed between higher ambient temperatures and stem-flow gauge error ( $r=0.05$, nonsignificant). This result does not agree with the findings of Shackel et al. (1992), who suggested that ambient conditions can impose a bias in gauge signals and, hence, influence gauge accuracy. In this regard, it was interesting to note that of the 30 runs conducted, the most accurate stemflow gauge estimate $(+0.4 \%)$ occurred on a day during which the maximum air temperature was highest (43.7C).

Transpiration estimates from stem-flow gauges and lysimeters for three of the 14-h diurnal runs were chosen to represent all species and irrigation treatments and to have diurnal runs with stem-flow gauge error estimates $<20 \%$ [10.1\%, 8.3\%, and $19.4 \%$ (Fig. $2 \mathrm{~A}-\mathrm{C}$, respectively)]. Transpiration estimates based on this shorter run time revealed that the gauges could reflect the diurnal transpiration changes recorded by the lysimeters in most

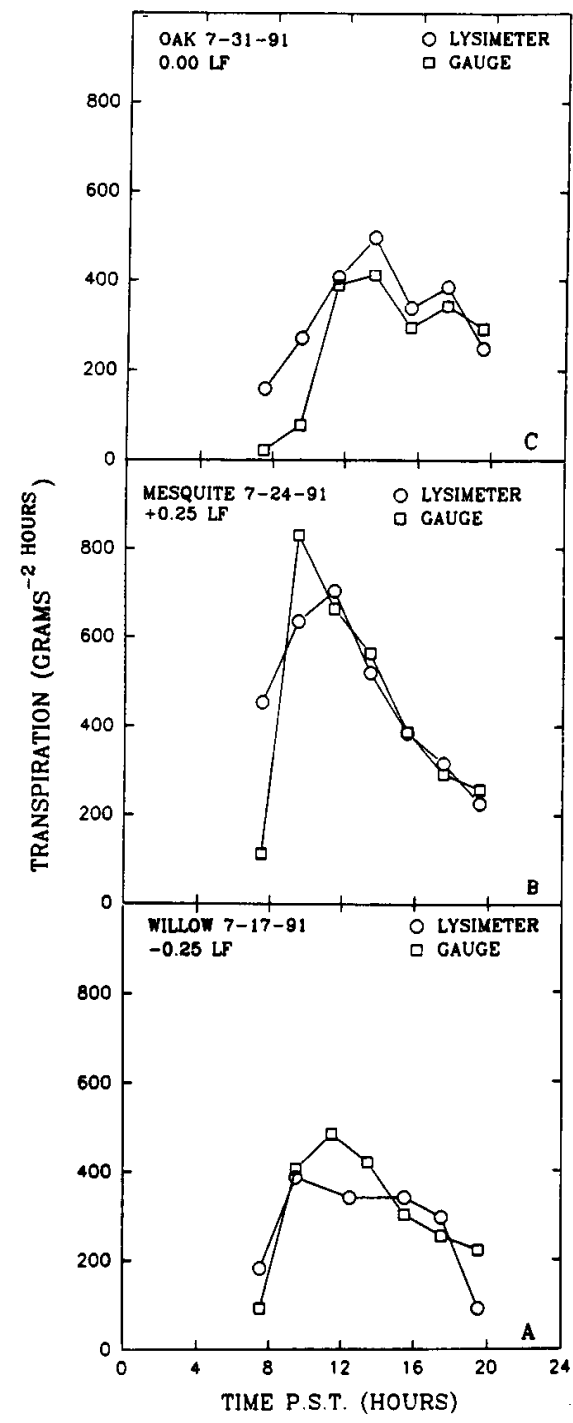

Fig. 2. Comparison of transpiration estimated from stem-flow gauges and lysimetry during 14-h (Pacific standard sime) diumal runs for a desert willow under a -0.25 leaching fraction (LF), an Argentine mesquite under $\mathrm{a}+0.25 \mathrm{LF}$, and a live oak under a $0.00 \mathrm{LF}$. 
cases. However, for most of the diurnal measurements conducted $(96 \%)$, the stem-flow gauges revealed a delayed response during the early morning measurements (0 to $400 \mathrm{~g} / 2-\mathrm{h}$ periods) (Fig. 2), which often significantly contributed to the estimated total error for these shorter periods. This early morning difference suggests a possible capacitance effect, as reported by Schulze et al. (1989).

Estimating evapotranspiration in the field is, to a certain degree, uncertain (storage change and drainage estimates). Any technique that will improve tree water-use estimates deserves further attention. The ability to estimate transpiration independent of soil evaporation is also an improvement over total evapotranspiration estimates when evaluating plant water status and water use in response to irrigation. Nondestructive techniques such as the stemflow gauge are promising in this regard. An average $18 \%$ error in this experiment and a $<10 \%$ error when predicted run times exceeded $68 \mathrm{~h}$ clearly suggest that this technique canestimate transpiration accurately to schedule woody ornamental irrigations in an arid environment. The time and money required to estimate tree water use in the field using lysimetry or other intensive water-balance approaches further supports the choice of using other techniques such as the stem-flow gauge.

\section{Literature Cited}

Biran, I., B. Bravdo, I. Bushkin-Harav, and E. Rawitz 1981. Water consumption and growth rate of 11 turfgrasses as affected by mowing height, irrigation frequency and soil moisture. Agron. J. 75 :8590.

Devitt, D.A., W.H. Jury, P. Stemberg, and L.H Stolzy. 1983. Comparison of methods used to estimate evapotranspiration for leaching control. Irr. Sci. 4:59-69.

Devitt, D.A., R.L. Morris, and D.C. Bowman. 1992. Evapotranspiration, crop coefficients and leaching fractions of irrigated desert turfgrass systems. Agron. J. 84:717-723.

Heilman, J.L. and J.M. Ham. 1990. Measurement of mass flow rate of sap in Ligustrum japonicum. HortScience 25:465-467.

Kim, K.S. and J.B. Beard. 1988. Comparative turfgrass evapotranspiration rates and associated plant morphological characteristics. Crop Sci. 28:328-331.

Knox, G.W. 1989. Water use and average growth index of five species of container grown woody landscape plants. J. Environ. Hort. 7: 136-139.

Schulze, E.D., J. Cermak, R. Matyssek, M. Penka,
R. Zimmermann, F. Vasicek, W. Gries, and J. Kucera. 1985. Canopy transpiration and water fluxes in the xylem of the trunk of Larix and Picea trees-A comparison of xylem flow, porometer and cuvette measurements. Oecologia 66:475-483.

Shackel, K.A., R.S. Johnson, C.K. Medawar, and C.J. Phene. 1992. Substantial errors in estimates of sap flow using the heat balance technique on woody stems under field conditions. J. Amer. Soc. Hort. Sci. 117:351-356.

Shearman, R.C. 1978. Water use rates and associated plant characteristics for twenty Kentucky bluegrass cultivars. Dept. of Hort., Univ. of Nebraska Turfgrass Res. Summary Prog. Rpt. 78:82.

Steinberg, S.L., C.H.M. van Bavel, and M.J. McFarland. 1989. A gauge to measure mass flow of sap in stems and trunks of woody plants. J. Amer. Soc. Hort. Sci. 114:466-472.

Steinberg, S.L., C.H.M. van Bavel, and M.J. McFarland. 1990. Improved sap flow gauge for woody and herbaceous plants. Agron. J. 82:851854.

Younger, V.B., A.W. Marsh, R.A. Strohman, V.A. Gibeault, and S. Spaulding. 1981. Water use and turf quality of warm season and cool season turfgrasses, p. 251-257. In: R.W. Sheard (ed.). Proc. Fourth Intl. Turf Res. Conf., Univ. of Guelph, Guelph, Ont., Canada. 